\title{
The Origin of EPR Signals in $\mathrm{SrCuO}_{2}$ Ceramics
}

\author{
M.A. Augustyniak-JabeOKow ${ }^{a}$, Yu.V. Yablokov ${ }^{a}$, \\ T.A. IVANOVA ${ }^{b}$, I. JACYNA-ONYSZKIEWICZ ${ }^{c}$ AND V.A. ShUSTOV ${ }^{b}$ \\ ${ }^{a}$ Institute of Molecular Physics, Polish Academy of Sciences \\ Smoluchowskiego 17, 60-179 Poznań, Poland \\ ${ }^{b}$ Kazan Physical Technical Institute, RAS \\ Sibirskii trakt 10/7, 420029 Kazan, Russia \\ ${ }^{c}$ Institute of Physics, A. Mickiewicz University, Poznań, Poland \\ The origin and thermal evolution of the EPR signals in $\mathrm{SrCuO}_{2}$ ceramics \\ are studied. It has been shown that the EPR signals observed in this ceramic \\ material are due to contamination with other phases. The axial signal is due \\ to $\mathrm{SrCu}(\mathrm{OH})_{4} \cdot \mathrm{H}_{2} \mathrm{O}$, which is a product of water reactions with $\mathrm{SrCuO}_{2}$. \\ PACS numbers: 75.50.Ee, 76.30.Fc, 81.05.Je
}

\section{Introduction}

$\mathrm{SrCuO}_{2}$ and $\mathrm{Sr}_{2} \mathrm{CuO}_{3}$ compounds are recognised as ideal systems of $1 \mathrm{D}$ $S=1 / 2$ antiferromagnetic Heisenberg chains with the exchange interaction $J$ estimated to be about $2200 \mathrm{~K}$ [1]. They should be EPR silent but EPR signals have been observed in the $\mathrm{SrCuO}_{2}$ and $\mathrm{Sr}_{2} \mathrm{CuO}_{3}$ ceramics [2, 3]. These signals have been usually assigned to structural defects breaking the antiferromagnetic interactions [2]. However, it has been established that exposition of $\mathrm{Sr}_{2} \mathrm{CuO}_{3}$ to humid air results in its decomposition $[4,5]$ and the decomposition products were identified by X-ray diffraction (XRD) phase analysis. The orthorhombic EPR signal of one of these products, namely $\mathrm{Sr}_{2} \mathrm{Cu}(\mathrm{OH})_{6}[5]$ is identical as that observed in $\mathrm{Sr}_{2} \mathrm{CuO}_{3}$ ceramics. A similar study of $\mathrm{SrCuO}_{2}$ has shown that this compound is much less sensitive to humid air and in [4] there is no information about XRD identification of any traces of $\mathrm{SrCuO}_{2}$ reaction with water. Nevertheless, results of [4] have put into the question the hypothesis that the EPR signal in $\mathrm{SrCuO}_{2}$ ceramic can be connected with structural defects. Additional hint for us was that 
in the samples of $\mathrm{SrCuO}_{2}$ doped with $\mathrm{K}^{+}$and $\mathrm{Li}^{+}$and stored for some years we have observed a signal identical to that observed in $\mathrm{Sr}_{2} \mathrm{CuO}_{3}$ [3].

The paper presents results concerning the influence of the presence of the admixture phases and the humid air on the EPR spectra of $\mathrm{SrCuO}_{2}$.

\section{Experimental}

\subsection{Synthesis}

Two $\mathrm{SrCuO}_{2}$ samples were prepared by a conventional solid- state reaction technique from mixtures of high purity raw materials: $\mathrm{CuO}$ and $\mathrm{SrCO}_{3}$ (Specpure, Johnson, Mattey Chemicals Limited). Two types of samples were prepared. To get sample (A) the compounds $\mathrm{CuO}$ and $\mathrm{SrCO}_{3}$ were mixed in appropriate proportions to obtain the stoichiometric material. The powder mixture was calcined initially in air at $1223 \mathrm{~K}$ for 10 hours, then the material was reground, pressed into tablets and sintered in air at $1223 \mathrm{~K}$ for 20 hours. The samples were then cooled in furnace to $773 \mathrm{~K}$ and quenched to room temperature. A similar procedure, but for a different nominal ratio of components $\mathrm{Sr}: \mathrm{Cu}=1.08: 0.92$ was used to obtain $\mathrm{Sr}_{1.08} \mathrm{Cu}_{0.92} \mathrm{O}_{2}$ labelled as sample (B). The samples were sintered in air, and then cooled in furnace to room temperature.

\subsection{Structural analysis}

Powder X-ray diffraction patterns were obtained with a DRON-2 diffractometer using Fe $K_{\alpha}$ radiation with $\beta$ filter. The data were analysed by the full profile analysis of Rietveld method. The program MAUDI.9992 [6] was used.

\subsection{EPR study}

The EPR spectra were recorded with a RADIOPAN SE/X-2547 spectrometer with $100 \mathrm{kHz}$ magnetic modulation, at room temperature and at $77 \mathrm{~K}$.

Fresh, as-prepared samples were studied not later than 2-3 hours after getting them out from the furnace. In this time samples were cut to small pieces, which were placed in the tubes. All handling was done in the air. Measurements were also carried on after exposition of the samples to steam and hot water and after consecutive steps of the thermal treatment.

\section{Results}

\subsection{Structural analysis}

Results of the structural analysis are presented in the Table. In sample (A) admixtures of 6.3 molar $\%$ of $\mathrm{Sr}_{14} \mathrm{Cu}_{24} \mathrm{O}_{41}$ and 1.4 molar $\%$ of $\mathrm{Sr}_{2} \mathrm{CuO}_{3}$ were found. In sample (B) 18.3 molar $\%$ of $\mathrm{Sr}_{2} \mathrm{CuO}_{3}$ and some small amounts of unidentified phases were detected. 
TABLE

Results of the structural phase analysis.

\begin{tabular}{l|c|c|c|c|c|c|c|c}
\hline \hline Compound & \multicolumn{4}{|c|}{ Sample (A) } & \multicolumn{4}{c}{ Sample (B) } \\
\cline { 2 - 9 } & Molar \% & $a[\AA]$ & $b[\AA]$ & $c[\AA]$ & Molar \% & $a[\AA]$ & $b[\AA]$ & $c[\AA]$ \\
\hline $\mathrm{SrCuO}_{2}$ & 92.3 & 3.571 & 16.323 & 3.911 & 79.6 & 3.571 & 16.322 & 3.911 \\
$\mathrm{Sr}_{2} \mathrm{CuO}_{3}$ & 1.4 & 3.930 & 3.508 & 12.837 & 18.3 & 3.913 & 3.502 & 12.702 \\
$\mathrm{Sr}_{14} \mathrm{Cu}_{24} \mathrm{O}_{41}$ & 6.3 & 11.475 & 13.345 & 27.656 & & & & \\
Unidentified & & & & & 2.1 & & &
\end{tabular}

\subsection{EPR study}

The spectra shown in Fig. 1 were recorded for the "as-prepared samples". An axial spectrum (a) of a fresh (A) sample is typical of the $\mathrm{SrCuO}_{2}$ compound with $g_{\|}=2.259$ and $g_{\perp}=2.055$. In the spectrum $(b)$ of the fresh sample (B) an

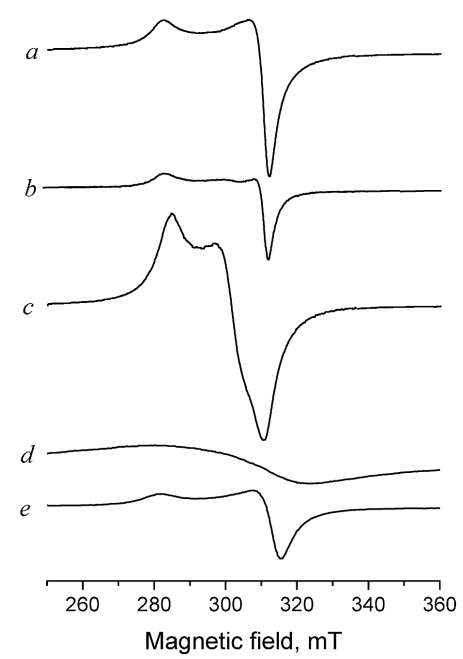

Fig. 1. The spectra of as-prepared samples; $a$ - fresh sample (A) $\mathrm{SrCuO}_{2} ; b$ - fresh sample (B) $\mathrm{Sr}_{1.08} \mathrm{Cu}_{0.92} \mathrm{O}_{2} ; c$ - the same sample (B) after $20 \mathrm{~h}$ storing in air; $d-$ $\mathrm{RT}$ spectrum of the sample (A1) stored in the closed container for 2 months; $e-$ the spectrum of the (A1) sample at $77 \mathrm{~K}$.

admixture of the orthorhombic signal is clearly seen. After 20 hours in air the axial signal in this sample has been transformed into the orthorhombic spectrum $(c)$ with $g_{x}=2.245, g_{y}=2.115$, and $g_{z}=2.051$ and with traces of the axial signal. The spectrum $(d)$ was recorded at RT for a sample (A) stored, in a small closed container under dry air for two months and marked as (A1). No traces of the axial signal were visible. The sample (A1) with the broad $(d)$ spectrum recorded at $77 \mathrm{~K}$ exhibits the axial spectrum $(e)$ with $g_{\|}=2.277$ and $g_{\perp}=2.045$. 
Exposition of the fresh $\mathrm{SrCuO}_{2}$ samples to humid air and to water results in a strong increase in the intensity without changing the form of the spectra (or, in the case of the stored sample (A1), in the appearance of the axial signal). A rapid, steam induced increase in the axial spectrum intensity was earlier reported [2]. In the case of a fresh as-prepared sample (B) the exposition to steam causes an increase in the axial and orthorhombic signals to the same degree and the spectrum shape remains the same as the spectrum $b$ in Fig. 1.

Small ceramic pieces of the studied ceramics, with a strong water-induced axial signal and a mass of about $20 \mathrm{mg}$ were immersed in silicone oil for isolation from the air. These samples were gradually annealed in the range of 383-453 K. At each temperature they were kept for 15 minutes, took out from the oven and cooled down to room temperature and then their EPR spectra were recorded. The results obtained for sample (A) are shown in Fig. 2. Heating the sample to the $110^{\circ} \mathrm{C}$ $(383 \mathrm{~K})$ results in a small increase in the axial spectrum intensity, but starting from $120^{\circ} \mathrm{C}(393 \mathrm{~K})$ up to $180^{\circ} \mathrm{C}(453 \mathrm{~K})$ a gradual transformation of the axial into the orthorhombic signal is observed. Additional heating at this temperature completes the process of transformation and the pure orthorhombic spectrum is observed.

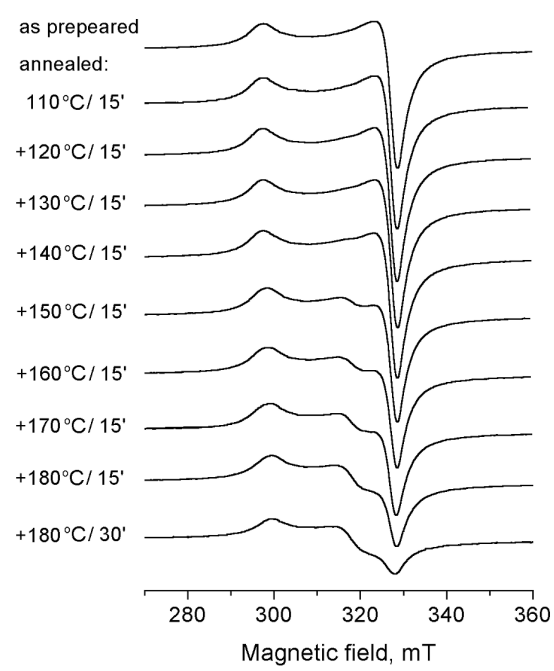

Fig. 2. The evolution of the water induced spectrum of sample (A) annealed at different temperatures.

For heating to higher temperatures the samples were isolated from humid air by a thick layer of $\mathrm{Al}_{2} \mathrm{O}_{3}$ powder. Annealing at temperatures above $250^{\circ} \mathrm{C}$ $(523 \mathrm{~K})$ affected the orthorhombic spectra, whose intensity gradually decreased. The process was similar for $\mathrm{SrCuO}_{2}(\mathrm{~A})$ and $\mathrm{Sr}_{1.08} \mathrm{Cu}_{0.92} \mathrm{O}_{2}$ (B) samples. After the final heating at $350^{\circ} \mathrm{C}(623 \mathrm{~K})$ only featureless broad lines are observed at room temperature (see Fig. 3). These lines transform with temperature decreasing. At 
$77 \mathrm{~K}$ the axial spectrum with $g_{\|}=2.277$ and $g_{\perp}=2.045$ is observed for the sample (A). The transformation of the signal of sample (B) is different and only a change in its linewidth from about $30 \mathrm{mT}$ at RT to about $19 \mathrm{mT}$ at $77 \mathrm{~K}$ (Fig. 3b) is observed.
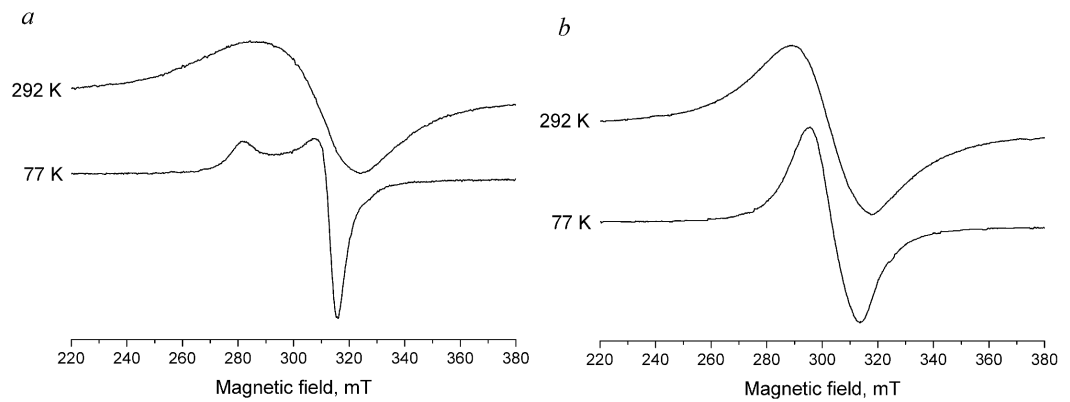

Fig. 3. The spectra of the samples annealed at $350^{\circ} \mathrm{C}$; (a) a broad EPR signal of a sample (A) transforms at $77 \mathrm{~K}$ to the axial spectrum; (b) a broad EPR signal of $\mathrm{CuO}$ in a sample (B) at $77 \mathrm{~K}$ becomes narrowed indicating the nanosized dimensions of $\mathrm{CuO}$ grains.

Exposition of the thermally treated samples with spectra presented in Fig. 3 to humid air, hot steam or water results in the appearance of orthorhombic spectrum. The presence of the axial spectrum often treated as the characteristic EPR spectrum of $\mathrm{SrCuO}_{2}$ ceramics can be detected only by the line shape analysis.

\section{Discussion}

$\mathrm{Sr}_{14} \mathrm{Cu}_{24} \mathrm{O}_{41}$ identified as the admixture phase in the sample (A) exhibits a strong EPR signal [7] with $g_{\|}=2.28 \pm 0.03$ and $g_{\perp}=2.04 \pm 0.02$. The linewidth of the EPR signal of the single $\mathrm{Sr}_{14} \mathrm{Cu}_{24} \mathrm{O}_{41}$ crystal, measured for the magnetic field along the narrower perpendicular direction, is about $27 \mathrm{mT}$ at RT and decreases to about $3 \mathrm{mT}$ at $77 \mathrm{~K}$. The admixture of $6 \%$ should result in a noticeable EPR signal. The principal values of $g$-factor, measured at $77 \mathrm{~K}$ and differences in the linewidth at RT and $77 \mathrm{~K}$ indicate that the EPR signal of the stored sample (A1) and the signal in samples (A) after annealing at high temperatures (Fig. 3a) can be ascribed to the admixture of $\mathrm{Sr}_{14} \mathrm{Cu}_{24} \mathrm{O}_{41}$ phase.

It was shown [2] and our observations have confirmed this that the intensity of the axial signal observed for $\mathrm{SrCuO}_{2}$ is sensitive to the moisture and increases strongly after direct exposition to water. We have shown also that the axial signal transforms with temperature to the orthorhombic one, which was assigned to $\mathrm{Sr}_{2} \mathrm{Cu}(\mathrm{OH})_{6}$ [4]. It suggests that the axial signal is due to another hydroxide of strontium and copper. The best candidate is $\mathrm{SrCu}(\mathrm{OH})_{4} \cdot \mathrm{H}_{2} \mathrm{O}$, which was studied as a possible precursor of the $\mathrm{SrCuO}_{2}$ phase [8, 9]. Its EPR spectrum is typical 
of the square-planar coordination of $\mathrm{Cu}^{2+}$ ion [10] with $g_{\|}=2.26$ and $g_{\perp}=2.06$ parameters very close to those of the $\mathrm{SrCuO}_{2}$ ceramics. The thermal decomposition of $\mathrm{SrCu}(\mathrm{OH})_{4} \cdot \mathrm{H}_{2} \mathrm{O}$ was studied [9] by differential scanning calorimetry (DSC) and XRD analysis was used for the products identification. It was found that in the temperature range of $120-180^{\circ} \mathrm{C}(393-453 \mathrm{~K}) 2$ molecules of $\mathrm{SrCu}(\mathrm{OH})_{4} \cdot \mathrm{H}_{2} \mathrm{O}$ loose 3 molecules of $\mathrm{H}_{2} \mathrm{O}$ and decompose into $\mathrm{Sr}_{2} \mathrm{Cu}(\mathrm{OH})_{6}$ and $\mathrm{CuO}$. Above $250^{\circ} \mathrm{C}$ next steps of dehydration were observed yielding $\mathrm{Sr}(\mathrm{OH})_{2}$ and $\mathrm{CuO}$. The final weight loss observed between 350 and $470^{\circ} \mathrm{C}$ involved the partial back reaction of strontium hydroxide and copper oxide to yield $\mathrm{Sr}_{2} \mathrm{CuO}_{3}$. The excess amount of $\mathrm{CuO}$ was detected in the sample [9].

The above-described transformations are fully consistent with the observed by us evolution of EPR spectra with temperature. The axial signal of $\mathrm{SrCu}(\mathrm{OH})_{4} \cdot \mathrm{H}_{2} \mathrm{O}$ transforms between $120^{\circ} \mathrm{C}(373 \mathrm{~K})$ and $180^{\circ} \mathrm{C}(553 \mathrm{~K})$ into the orthorhombic one of $\mathrm{Sr}_{2} \mathrm{Cu}(\mathrm{OH})_{6}$. This compound decomposes to the diamagnetic $\mathrm{Sr}(\mathrm{OH})_{2}$ and $\mathrm{CuO}$, whose signal is very broad. As the $\mathrm{CuO}$ is the only paramagnetic product of thermal decomposition the broad signal observed for sample (B) annealed at $623 \mathrm{~K}$ (Fig. 3b) should be assigned to $\mathrm{CuO}$. In the crystalline $\mathrm{CuO}$ with Néel temperature $T_{\mathrm{N}}=230 \mathrm{~K}$ lowering temperature down to $77 \mathrm{~K}$ results in the strong increase in the resonant linewidth and the EPR spectra is hardly detectable. However, in nano-powders a shift of the Néel temperature down to $40 \mathrm{~K}$ is observed [11]. Therefore, the observed decrease in the linewidth (Fig. 3b) suggests the nanosize dimensions of the $\mathrm{CuO}$ crystallites.

The signal with orthorhombic symmetry (Fig. 1c) observed in samples (B) kept in air is a result of an admixture of 19.6 molar \% of $\mathrm{Sr}_{2} \mathrm{CuO}_{3}$ phase. As this phase is more reactive than $\mathrm{SrCuO}_{2}$ on the beginning of water decomposition of the sample the signal of $\mathrm{Sr}_{2} \mathrm{Cu}(\mathrm{OH})_{6}$ predominates the signal of $\mathrm{SrCu}(\mathrm{OH})_{4} \cdot \mathrm{H}_{2} \mathrm{O}$. However, when the whole surface phase of $\mathrm{Sr}_{2} \mathrm{CuO}_{3}$ has been already decomposed, the less effective decomposition of $\mathrm{SrCuO}_{2}$ phase results in an increase in the axial signal intensity. The back reaction and $\mathrm{Sr}_{2} \mathrm{CuO}_{3}$ synthesis can explain the appearance of the orthorhombic signals in the samples exposed to water earlier subjected to the thermal treatment. This compound reacts readily with moisture and yields the orthorhombic signal. At the same time a layer of the $\mathrm{CuO}$ dispersed on the ceramic surface together with $\mathrm{Sr}_{2} \mathrm{CuO}_{3}$ and $\mathrm{Sr}_{2} \mathrm{Cu}(\mathrm{OH})_{6}$ protect the surface and the bulk of $\mathrm{SrCuO}_{2}$ from contact with water, so the axial signal becomes only an admixture to the orthorhombic one.

\section{Conclusions}

The EPR signals observed in the $\mathrm{SrCuO}_{2}$ ceramics are due to the contamination with other phases and decomposition of the ceramic surface caused by water. 


\section{References}

[1] N. Motoyama, H. Eisaki, S. Uchida, Phys. Rev. Lett. 76, 3212 (1996).

[2] H. Ohta, N. Yamuchi, M. Motokava, M. Azuma, M. Takano, J. Phys. Soc. Jpn. 61, 3370 (1992).

[3] T.A. Ivanova. I. Jacyna-Onyszkiewicz, M.A. Augustyniak-Jabłokow, Yu.V. Yablokov, V.A. Shustov, accepted for Phys. Solid State (Russian).

[4] Y.H. Wang, B.A. Scott, B.H. Chen, D. Walker, Physica C 275, 52 (1997).

[5] J.M. Hill, D.C. Johnston, L.L. Miller, Phys. Rev. B 65, 134428 (2002).

[6] The Rietveld Method, Ed. R.A. Young, Oxford University Press, New York 1993.

[7] V. Kataev, K.-Y. Choi, M. Grüninger, U. Ammerahl, B. Büchner, A. Freimuth, A. Revcolevschi, Phys. Rev. B 64, 104422 (2001).

[8] M. Kato, I. Nagai, Y. Koike, Solid State Ionics 108, 275 (1998).

[9] M. Kato, T. Miyajima, I. Nagai, Y. Koike, J. Low Temp. Phys. 105, 1499 (1996).

[10] M.J. Pack, W. Patalinghug, M.T. Weller, J. Chem. Soc., Dalton Trans. , 7 (1996).

[11] A. Punnose, M.S. Seehra, J. Appl. Phys. 91, 7766 (2002). 